\title{
Zinc, Copper and Oxidative stresses in Chronic Pancreatitis
}

\section{Kshaunish Das}

Over the last two decades, critical advances in genomics and pancreatic stellate cell biology has led to the evolution of our understanding of chronic pancreatitis from an "enigmatic process of uncertain pathogenesis" to a "fibro-inflammatory syndrome" developing as a result of a "persistent pathological response" to pancreatic parenchymal injury in individuals who are genetically pre-disposed and/or environmentally exposed to toxins, either known (e.g. alcohol, smoking, autoimmunity) or unknown ${ }^{1,2}$. Within the framework of the latter, there is a tacit acknowledgement that we have not yet identified all the risk factors, genetic or otherwise, that predispose an individual to developing chronic pancreatitis. This is especially relevant for the vast majority of patients suffering from idiopathic chronic pancreatitis, including its variant tropical calcific pancreatitis, which is more prevalent in India. Moreover, it might explain why only a minority of alcoholics develop chronic pancreatitis in their lifetime.

One of the prominent theories propounded to explain the etio-pathogenesis of chronic pancreatitis, both alcoholic and idiopathic, is the "oxidative-stress hypothesis". According to this hypothesis, recurrent or persistent pancreatic parenchymal (acinar) injury occurs due to a lack of sufficient quantities of protective anti-oxidants (predominantly dietary) to counter the increased production of reactive oxygen species (via xenobiotic metabolism) by the over-induced microsomal oxidases (due to exposure to alcohol, smoking, environmental hydrocarbons etc.) ${ }^{3}$. The theory is the basis of anti-oxidant supplementation in patients with chronic pancreatitis ${ }^{4,5}$.

Zinc $(\mathrm{Zn})$ and copper $(\mathrm{Cu})$ are essential dietary trace metals. They are type 2 nutrients, i.e., deficiency of these produce multiple non-specific general shifts in metabolism resulting in poor growth or neurocognitive impairments ${ }^{6,7}$. Over 300 metalloenzymes (including anti-oxidants) require $\mathrm{Zn}$ as a catalyst, and almost 2500 human transcription factors require $\mathrm{Zn}$ to maintain their structural integrity. Similarly, $\mathrm{Cu}$ is an essential component of over 50 different enzymes, including the $\mathrm{Cu} / \mathrm{Zn}$ Superoxide Dismutase (SOD) essential for free-radical detoxification. They are both toxic in supra-physiologic amounts. This is especially true for $\mathrm{Cu}$, which produces highly toxic reactive oxygen species (ROS) due to its special redox chemistry. This is manifested in the severe hepatocyte and neuronal injuries in Wilson's Disease where $\mathrm{Cu}$ overload occurs due to genetic defects in $\mathrm{Cu}$ excretion ${ }^{7}$. In humans, these metals have a limited storage pool, and depend almost exclusively on nutritional intake to meet physiological needs ${ }^{6,7}$. Their blood and tissue levels are tightly regulated either at the level of uptake or excretion, intestinal $(\mathrm{Zn})$ or biliary $(\mathrm{Cu})^{6,7}$. In what may be considered over-simplification, it can be propounded that, within the paradigm of chronic pancreatitis, $\mathrm{Zn}$ has considerable anti-oxidant properties while $\mathrm{Cu}$, even in 
minimally enhanced amounts, can cause serious oxidative damage to acinar cells.

In this issue of the journal, Girish et. al. ${ }^{8}$, demonstrate that a mixed cohort of patients, suffering from alcoholic and tropical chronic pancreatitis, have a lower $\mathrm{Zn}$ and higher $\mathrm{Cu}$ levels in erythrocytes vis-à-vis healthy matched controls. These findings were more pronounced in those with more advanced chronic pancreatitis, manifested either by exocrine (low fecal elastase) or endocrine (diabetes) insufficiency. Additionally, serum levels of anti-oxidants were lower and serum markers of lipid peroxidation were higher in patients with chronic pancreatitis as compared to the controls. In the second part of the article, the authors go on to propose that erythrocyte $\mathrm{Zn} / \mathrm{Cu}$ ratio can be a used as a non-invasive marker of exocrine and endocrine insufficiency in patients with chronic pancreatitis.

Where do these findings stand in today's understanding of chronic pancreatitis? The first part of the study recapitulates previous reports by the authors own group as well as those from European cohorts ${ }^{9-13}$. This confirms that alterations in these heavy metals, favouring a pro-oxidant injury to the exocrine pancreas, is a global phenomenon in chronic pancreatitis, irrespective of etiology. However, association does not imply causality. Where can we go from here? Firstly, these findings need to be confirmed in a larger cohort of patients and controls. Secondly, we need to find out if chronic pancreatitis is more common in those with documented $\mathrm{Zn}$ deficiency either by a casecontrol or cohort design. This can be done by tapping into existing databases of nutritional sample surveys including serum/plasma $\mathrm{Zn}$ and/or $\mathrm{Cu}$ levels, have already been conducted worldwide.

The authors' proposal about erythrocyte $\mathrm{Zn} / \mathrm{Cu}$ ratio as a marker for pancreatic insufficiency needs further validation. Previous studies had reported that pancreatic $\mathrm{Zn}$ output correlated strongly with enzyme secretion ${ }^{10}$. Despite the initial enthusiaism of using $\mathrm{Zn}$ concentration in secretin-stimulated duodenal juice as a potent measure of pancreatic exocrine insufficiency, this was not validated in independent cohorts later on ${ }^{14-16}$. Thus direct measurements of $\mathrm{Zn}$ in pancreatic exocrine secretions as a measure of pancreatic exocrine insufficiency underwent a silent burial.
Diabetes is a common complication of advanced chronic pancreatitis. The prevalence of low $\mathrm{Zn}$ and elevated $\mathrm{Cu}$ in chronic pancreatitis with diabetes has been documented in previous reports ${ }^{11,13}$. $\mathrm{Zn}$ is essential for normal processing and storage of insulin in human pancreatic $\beta$-cells and it exerts an insulin-mimetic and anti-diabetic effect in humans ${ }^{17,18}$. A healthy pancreas has a high $\mathrm{Zn}$ content. Most of it is contained in the $\beta$-cells, concentrated in the dense core insulin secreting granules $(\mathrm{ISG})^{17}$. Hypozincemia has been reported in both type 1 and 2 diabetic patients, with partial amelioration of hyperglycemic state in these individuals with oral $\mathrm{Zn}$-supplementation ${ }^{18,19}$. The understanding of the mechanistic basis of this intimate relationship between $\mathrm{Zn}$ and diabetes received a fillip when genome-wide association studies (GWAS) identified variants in human SLC30A8 gene affected the risk of development of type 2 diabetes ${ }^{20}$. This gene encodes the zinc transporter ZnT8 that is selectively expressed on the secretory granules of pancreatic islet $\beta$ and $\alpha$ cells. Individuals carrying the risk variants of this gene have impaired insulin secretion and lower $\beta$ cell function and, consequently, are the ones who respond best to $\mathrm{Zn}$-supplementation ${ }^{18}$. Thus, the question arises whether the lower $\mathrm{Zn}$ levels in the present study is the result of diabetes secondary to chronic pancreatitis (type 3 diabetes) or due to diabetes per se. Moreover, it would be interesting to unravel whether the SLC30A8 gene has any role in tropical pancreatitis where diabetes occurs quite early.In conclusion, the present study is a step forward in discovering the non-traditional environmental risk factors for the development of chronic pancreatitis and pancreatic diabetes.

\section{References}

1. Steer ML, WI Freedman S. Chronic Pancreatitis. New Eng J Med 1995; 332: 1482-90.

2. Whitcomb DC, Frulloni L, Garg P, Greer JB, Schneider A, Yadav D, Shimosegawa T. Chronic pancreatitis: An international draft consensus proposal for a new mechanistic definition. Pancreatology 2016; 16: 218-24.

3. Braganza JM. A Framework for the Aetiogenesis of Chronic Pancreatitis. Digestion 1998; 59 (S): 1-12.

4. Bhardwaj P, Garg PK, Maulik SK, Saraya A, Tandon 
RK, Acharya SK. A Randomized Controlled Trial of Antioxidant Supplementation for Pain Relief in Patients With Chronic Pancreatitis. Gastroenterol 2009; 136: 149-59.

5. Talukdar R, Murthy HVV, Reddy DN. Role of methionine containing antioxidant combination in the management of pain in chronic pancreatitis: A systematic review and meta-analysis. Pancreatology 2015; 15: 136-44.

6. King JC, Brown KH, Gibson RS, Krebs NF, Lowe NM, Seikmann JH, Raiten DJ. Biomarkers of Nutrition for Development (BOND)-Zinc Review. J Nutr 2016; 146(S): 858S-85S.

7. Peña MMO, Lee J, Thiele DJ. A Delicate Balance: Homeostatic Control of Copper Uptake and Distribution. J Nutr 1999; 129: 1251-60.

8. Girish BN, Rajesh G, Vaidyanathan K, Ballakrishnan V. Zinc/copper ratio: a predictor of pancreatic function in chronic pancreatitis? Trop Gastro 2016:37(1)

9. Girish BN, Rajesh G, Vaidyanathan K, Ballakrishnan V. Zinc Status in Chronic Pancreatitis and its Relationship with Exocrine and Endocrine Insufficiency. JOP 2009; 10: 651-6.

10. Gjørup I, Petronijevic L, Rubenstein E, Anderson B, Worning H, Burcharth F. Pancreatic Secretion of Zinc and Copper in Normal Subjects and in patients with Chronic Pancreatitis. Digestion 1991; 49: 161-6.

11. Quilliot D, Dousset B, Guerci B, Dubois F, Drouin P, Zeigler O. Evidence That Diabetes Mellitus Favors Impaired Metabolism of Zinc, Copper, and Selenium in Chronic Pancreatitis. Pancreas 2001; 22: 299-306.

12. Milnerowicz H, Jablonowska M, Bizoń A. Change of
Zinc, Copper, and Metallothionein Concentrations and the Copper-Zinc Superoxide Dismutase Activity in Patients With Pancreatitis. Pancreas 2009; 38: 681-8.

13. Quilliot D, Walters E, Bonte J-P, Fruchart J-C, Duriez P, Zeigler O. Diabetes mellitus worsens antioxidant status in patients with chronic pancreatitis. AM JClin Nutr 2005; 81: 1117-25.

14. Domínguez-Muñoz JE, Martinez SM, Leodolter A, Malfertheiner P. Quantification of Pancreatic Zinc Output as Pancreatic Function Test: Making the Secretin - Caerulein Test Applicable to Clinical Practice. Pancreatology 2004; 4: 57-62.

15. Pungpapong S, Scolapio JS, Woodward TA, Wallace MB, Raimondo M. Is Zinc Concentration in Pancreatic Fluid a Marker for Pancreatic Diseases? JOP 2005; 6: 425-30.

16. Jensen NM, Larsen S. A Rapid, Endoscopic Exocrine Pancreatic Function Test and the Lundh Test: A Comparative Study. Pancreatology 2008; 8: 617-24.

17. P. Chabosseau, G.A. Rutter. Zinc and diabetes. Archives of Biochemistry and Biophysics (2016), http:// dx.doi.org/10.1016/j.abb.2016.05.022.

18. Vardatsikos G, Pandey NR, Srivastava AK. Insulinomimetic and anti-diabetic effects of zinc. J Inorganic Biochem 2013; 120: 8-17.

19. Jayawardena R, Ranasinghe P, Galappatthy P, Malkanthi RLDK, Constantine GR, Katulanda P. Effects of zinc supplementation on diabetes mellitus: a systematic review and meta-analysis. Diabetology e Metabolic Syndrome 2012, 4:13.

20. G.A. Rutter, F. Chimienti. SLC30A8 mutations in type 2 diabetes. Diabetologia 2015; 58: 31-36. 